\title{
Analysing the Possibility of Extracting Energy from Ocean Waves in Cabo-Verde to Produce Clean Electricity - Case- Study: The Leeward Islands
}

\author{
Wilson M.L. Monteiro ${ }^{a^{*}}$ and António Sarmento ${ }^{b}$ \\ a Faculty of Science and Technology, University of Cabo-Verde, Palmarejo Campus, 279C-Praia Cabo-Verde \\ ${ }^{\text {b } L i s b o n ~ H i g h ~ T e c h n i c a l ~ I n s t i t u t e, ~ T e c h n i c a l ~ U n i v e r s i t y ~ o f ~ L i s b o n, ~ A l a m e d a ~ C a m p u s, ~ C P ~} 1049$-001- Lisbon, Portugal
}

\begin{abstract}
This work analyses the possibility of extracting energy from the ocean waves around the Leeward Islands of Cabo-Verde. This study was based on 31 years of wave and wind data, obtained through the SOWFIA - Streamlining of Ocean Wave Farm Impact Assessment, at $16^{\circ} \mathrm{N}-24^{\circ} \mathrm{W}$. Then, the SWAN - Simulating Waves Nearshores - was used to perform the wave transformations to the shore. As the number of waves is very high, the cluster analysis and the Non-Parametric Wilcoxon Test were used to reduce the computing time by SWAN. The results pointed to the South of these islands and the East Coast of Maio island as the best locations for wave energy extraction. The use of the power matrix of some commercial devices that are available, such as Wave Dragon (7 MW), Pelamis (750 kW) and AquaBuoy $(250 \mathrm{~kW})$, allowed to estimate the best devices scale factors that leads to their best Capacity Factor (CF), at the target regions. Thus, the Wave Dragon is the most indicated device $(\mathrm{CF}=71 \%)$, at the scale of 0.3 , followed by AquaBuoy scaled by $0.4(\mathrm{CF}=57 \%)$ and Pelamis scaled by 0.5 , with $\mathrm{CF}=26 \%$. However, in a natural scale, AquaBuoy is the most efficient device $(\mathrm{CF}=18.8 \%)$ in comparison to the Wave Dragon $(\mathrm{CF}=17 \%)$ and Pelamis $(\mathrm{CF}=15 \%)$. AquaBuoy presented the best cost-benefit ratio $(\mathrm{C} / \mathrm{B}=0.135 \mathrm{USD} / \mathrm{kWh})$ followed by Wave Dragon $(\mathrm{C} / \mathrm{B}=0.235 \mathrm{USD} / \mathrm{kWh})$ and Pelamis $(\mathrm{C} / \mathrm{B}=0.390 \mathrm{USD} / \mathrm{kWh})$. The limitation of the number of Wave Energy Converters to implement the wave power plant affects negatively the cost of its investment.
\end{abstract}

C2019. CBIORE-IJRED. All rights reserved

Keywords: Wave Energy; Cluster Analysis; Wilcoxon Test; Cabo-Verde; Leeward Islands

Article History: Received March 27 th 2018; Received in revised form October 16 $6^{\text {th }}$ 2018; Accepted January $5^{\text {th }}$ 2019; Available online

How to Cite This Article: Monteiro, W.M.L., and Sarmento, A (2019). Analysing the Possibility of Extracting Energy from Ocean Waves in CaboVerde to Produce Clean Electricity - Case-Study: The Leeward Islands. Int. Journal of Renewable Energy Development, 8(1), 103-112 https://doi.org/10.14710/ijred.8.1.103-112

\section{Introduction}

The energy associated with the manifestation of ocean waves is an expression of the solar energy that currently competes to produce clean electricity. The global wave energy resource is estimated in 2TW, and the most energetic regions are those located at latitude between 30 ${ }^{\circ}$ and $60^{\circ}$, because of the strong wind that blows from the west (its prevalence was recorded there). The West Coast of Europe, South of America, Littorals of Canada and the South Coast of Australia are the most energetic areas in the world (Boyle, 2004). Although the development of the first Wave Energy Converters (WEC) dates back to 1799, modern research into WECs begun in late 1970s caused by the oil crisis and when Stephen Salter published, an article in 1974 (Salter, 1974). Since then, many prototypes of WECs have been developed and tested around the world (Koca et al 2013). These WECs are classified according to their conversion principles, location, directional characteristics and power take-off system (Kempner, 2014; EMEC, 2018). The studies conducted by many researchers and companies show that these prototypes can become commercially viable for large-scale commercial wave farms. Such wave farms are being planned on the coastlines of Europe, America and Australia (SCIRO, 2012; Pelamis, 2014 ; SIOCEAN, 2014).

The WEC industry is dominated by the USA, with 24 WECs and UK with 17 WECs. However, the UK is still the global leader of this industry, in terms of technological maturity and it is followed by the USA and Australia (Koca et. al, 2013). Between 2006 and 2013 the numbers of WECs under development increased drastically going from 53 to 147 . The sector is actually dominated by point absorber type WECs ( $\approx 46 \%$ ), followed by oscillating wave surge converter type WECs $(\approx 16 \%)$ and oscillating water column type WECs ( $\approx 15 \%)$. Forty-nine prototypes are currently being tested at sea, while fifteen prototypes are now undergoing at full or near full scale (grid connected) (Koca et al. 2013). Some grid-connected WECs, such as Pelamis, Wave Dragon, Limpet, AquaBuoy and Eco Wave Power, have already demonstrated their good stability and efficiency.

\footnotetext{
* Corresponding author: wilson.monteiro@docente.unicv.edu.cv
} 
Cabo-Verde is an archipelago of ten islands in the Atlantic Ocean, off the West Coast of Africa, with roughly half million people. The country is totally dependent on oil that is used to produce electricity. Electricity bill is, in Cabo-Verde, the most expensive in Africa. It is around 0.28 Euro/kWh (Electra, 2012) versus 0.17 Euro/kWh (Selenec, 2015) in Senegal, which is a neighboring country in the main land Africa. Some investments were made by the Government of Cabo-Verde aimed to introduce renewable sources of energy in the country, mainly solar and wind energy. The Renewable Energy Plan for CaboVerde (ERPCV) has defined an ambitious goal of achieving $50 \%$ of Renewable Energy implementation in the country by 2020 (GESTO, 2011). As a result of the ERPCV, there are four wind energy farms, in the country, with a total annual production of 80 to $110 \mathrm{GWh}$, and two solar energy farms with 7.5 MWp (MWp- Mega Watt Peak) (GESTO, 2011).

The leeward islands of Cabo-Verde are Santiago (the biggest island), Brava, Maio and Fogo. According to the most recent data collected by Electra (Electra, 2016) (Table 1), the total energy production in the referred group of islands is distributed through 7 thermal power plants (74.2\%), 1 solar farm (1.4\%) and 1 wind farm (13.2\%). Santiago is the biggest electricity producer (77.7\%), followed by Fogo (5.5\%), Maio and Brava (1.1\% each one). Only $53.8 \%$ of the energy produced is sold. The remaining $46.2 \%$ are distributed for internal consumption (9.5\%) and losses (36.7\%).

Table 1

Energy production, in $\mathrm{kWh}$, for Cabo-Verde's Leeward islands (Electra, 2016).

\begin{tabular}{lccc}
\hline Island & $\begin{array}{c}\text { Thermal } \\
\text { power plant }\end{array}$ & $\begin{array}{c}\text { Wind power } \\
\text { plant }\end{array}$ & $\begin{array}{c}\text { Solar } \\
\text { power } \\
\text { plant }\end{array}$ \\
\hline Santiago & 189380133 & 32121840 & 3495344 \\
Maio & 2708270 & 0 & 0 \\
Fogo & 13418555 & 0 & 0 \\
Brava & 2683872 & 0 & 0 \\
\hline
\end{tabular}

Because of its insular nature, most of Cabo-Verde's economic activities (around 90\%) are concentrated in coastal areas (Carvalho, 2013). In this context, it makes sense to use wave energy for producing electricity locally. Between 1999 and 2011, some research projects on ocean energy were initiated in the country, and they focused on Ocean Thermal Energy Conversion (OTEC) system and WaveStar technology (Wave energy). Unfortunately, these projects did not produce any visible results since they lacked an institutional framework that needs to be developed. In 2011, GESTO Energy, a Portuguese company, carried out an evaluation of the wave resources in Cabo-Verde based on eleven years during which they collected data from meteorological wave model worldwide. The data of direction, period and significant wave height were characterized and the values of these parameters were used for calculating the offshore annual average wave power (GESTO, 2011). According to this study, the islands that presented the best potential for wave energy exploration are: Sal, S. Antão, S. Vicente and Boa Vista. In fact, four projects for offshore wave energy conversion, based on the Pelamis technology, were proposed for these islands (GESTO, 2011): Sal (3.7 MW), S. Antão (3.7 MW), S.Vicente (3.7 MW) and Boavista (3.5MW). The study was commissioned by the Ministry of Tourism, Industry and Energy of Cabo-Verde, and unfortunately, the scientific results of the study are unknown since it was never published in any scientific journal or conferences.

In 2014, an American company, the Resolute Marine Energy (RME), presented, on the São Vicente island, the Wave2o Energy Project, aimed at developing, on that island, technical studies directed to design a system that can produce desalinated water based only on the wave energy resources (Wave 2oTM, 2015).

The available offshore wave power in the middle of Cabo-Verde presented low annual and monthly variation with an annual average value around $16 \mathrm{~kW} / \mathrm{m}$. At this location, once every hundred years, is possible to appear waves with a height close of $4 \mathrm{~m}$ (Monteiro and Sarmento, 2014). The most and least energetic months are, respectively, January $(23.49 \mathrm{~kW} / \mathrm{m})$ and July $(15.04$ $\mathrm{kW} / \mathrm{m})$. In fact, the monthly average power decays from January to July and increases from July to December $(21.21 \mathrm{~kW} / \mathrm{m})$ (Monteiro et al., 2017). Yet, these researchers introduce the methodology to evaluate the utilization of the Natural Caves in the context of onshore wave energy extraction, as a way to reduce the civil cost of a wave power plant based on the Oscillating Water Column principle (Monteiro et al., 2017).

\section{Methodology}

This study makes the evaluation of the real possibility of extracting energy from ocean waves around the leeward islands of Cabo-Verde. The analysis is carried out based on the following topics.

\subsection{Data Acquisition (SOWFIA) and Wave Transformation (SWAN)}

SOWFIA-Streamlining of Ocean Wave Farm Impact Assessment is an EU Intelligent Energy Europe Project with the goal of sharing and consolidating pan-European experience and best practices for consenting processes and environmental and socioeconomic impact assessment (IA) for offshore wave energy conversion developments (MoraFigueroa et al 2011). This project brings together ten partners across eight EU Member States actively involved in planned wave farm test centers and aims at providing recommendations for streamlining of IA approval processes with the purpose of removing legal, environmental and socioeconomic barriers associated with the development of the wave energy farms. The SOWFIA project uses data obtained from direct measurements (wave buoy) of the wave climate, carried out at the seven European wave energy test centers, through the Data Management Platform (DMP) tool. DMP is an interactive tool designed to assist in the decision-making process, providing information on different wave energy, monitoring activities at different test centers, and allowing direct visualization and downloading of relevant data. The DMP is publicly available on the SOWFIA website. The seven European test centers involved in the SOWFIA project are the AMETS (Ireland), BIMEP (Spain), Lysekil (Sweden), Ocean Plug (Portugal), SEAREV (France), Wave Hub (United Kingdom) and EMEC (Scotland) (Mora-Figueroa et al., 2011). As far as other regions of the ocean, where there are no in situ data measurements, the SOWFIA project uses data produced by WaveWatch 3 (WW3) wave model. The WW3 is phase- 
average model that solves the spectral action density balance equation for wavenumber-direction spectra. The Governing equation includes refraction due to the temporal and spatial variation of the mean water depth and current. The source terms include nonlinear interactions, dissipation due to the white capping, bottom friction, wind, wave growth and decay (Tolman, 1999). An important constraint of the formulation of the WW3 is that the parameterizations of the physical process, included in the model, do not address conditions where the waves are strong depth limited. This constraint implies that the model is generally applied on spatial scales between 20 and $100 \mathrm{~km}$ outside of the surfing zone (Tolman, 1999). In the same way as other sources of renewable energy, the nature of ocean waves is complex and impossible to be predicted in a precise manner. The data produced by WW3 model must be, wherever possible, calibrated with in situ measurements using wave buoy or altimeter data. Both calibrations of the wave data and the estimation of the confidence bounds are made difficult by the complex structure of errors in the model data. Error in parameters from wave model show nonlinear dependence on a variety of factors, seasonal and inter-annual changes in bias and short-term temporal correlation (Mackay et al., 2010). To assess the uncertainty associated with the estimation of the energy yield from a wave energy converter (WEC), Mackay et al (2010) used two hindcasts from the European Marine Energy Centre in Orkney. These hindcasts are produced by WAM (Komen et al 1994) and WW3 wave models and calibrated using a Datawell Directional Waverider buoy moored in $50 \mathrm{~m}$ water depth at the EMEC site. The study shows that before wave data calibration, the estimation of the long-term mean WEC power from the two hindcasts differ $20 \%$. After calibration this difference is reduced to $5 \%$.

The SWAN (Simulating Waves Nearshore), developed at the Technical University of Delft (TU-Delft), in Holland, is a third-generation numerical model that allows to obtain a set of parameters to characterize the wave climate in shallow water regions (Booji et al 1999). Based on the balance equation of the Spectral Variance, the SWAN was designed to complete the third-generation models developed for deep waters. The model propagates, in the geographic domain, the Directional Spectrum and calculates the evolution of waves generated by shorelines winds. The mathematical model involves not only the generation phenomenon, dissipation and nonlinear interaction between four characteristic waves, but also the process that exists in shallow water, such as dissipation due to bottom friction, nonlinear interaction between three waves and the wave breaking induced by the decrease of water depth (Booji et al 1999).

The present study was based on 31 years of wave and wind time-series data obtained from the SOWFIA Project at the location $16^{\circ} \mathrm{N}-24^{\circ} \mathrm{W}$ (at the middle of the country). Then, using the SWAN software, together with the bathymetric information on the location of study, the wave transformation from the point of data acquisition to the shorelines of the leeward group of islands was performed. The results produced by SWAN allowed mapping the wave characteristics around the target islands and to identifying the most frequent wave climate occurrences.

\subsection{The k-mean non-hierarchical clustering and the non- parametric Wilcoxon test}

The cluster analysis is a dissimilarity measurement based on two methods: the hierarchical (Tree) and nonhierarchical (k-mean). It is completely absent of any particular statistical method or model as well as any specific type of data distribution (Norusis, 2010). The kmean method defines a prototype in terms of a centroid, which is usually the mean of a group of points and is typically applied to objects in a continuous n-dimensional space. The input parameters of the k-mean techniques are the $\mathrm{k}$ value (the number of groups) and a set of points (data). Then, each point is assigned to the closest centroid and each collection of points assigned to a centroid of the cluster. The centroid of each cluster is then updated based on the points assigned to the cluster. The procedure is repeated until no point changes clusters, or equivalently, until the centroids remain the same. The proximity measurements to quantify the notion of the "closest" are based on the Euclidean Distance between points (Tan et al., 2005). The basic steps of the k-mean algorithm are described in a table below.

\section{Table 2}

Basic k-mean Algorithm.

1. Select $\mathrm{k}$ points as initial centroids

2. Repeat

3. Form $\mathrm{k}$ clusters by assigning each point to its closest centroid

4. Recompute the centroid of each cluster

5. Until centroid does not change

Because the quantity of waves to be transformed is very high (90584), the statistic cluster analysis in R Software, through the k-mean method, is used to reduce the computing time by SWAN, grouping the waves and winds with similar characteristics. Each group of waves and winds were replaced by a unique wave-wind combination and their characteristics were obtained through the NonParametric Wilcoxon Test (Weaver et al., 2017). With this procedure the SWAN's computing time is reduced drastically. As far as this study, the best $\mathrm{k}$ value was calculated using the GMDH Shell DS software (GMDH) through the elbow method (Bholowalia and Kumar, 2014) and the cluster analysis was then made using the RSoftware.

\subsection{Dynamic Similitude and the Capacity Factor}

In order to assess the different ratings of the devices (Wave Dragon, AquaBuoy and Pelamis) for the target site, their original power matrix was scaled, using the Froude Similitude, expressed by the following equation, in which $F r$ is the Froude Number, $v$ is the fluid velocity, $g$ is the gravitational constant and $l$ a characteristic length (Nakayama and Boucher, 1999).

$$
F r=\frac{v}{\sqrt{g l}}
$$

The dynamic similitude is then achieved when the Froude Numbers in the model and Prototype are the same. Hence, based on Froude Similitude, the scale factor is $\lambda=$ $l_{\text {model }} / l_{\text {prototype }}$. Finally, according to Hughes (Hughes, 1993) and Payne (Payne, 2008) the results in the power, wave height and wave peak period, in terms of $\lambda$ are expressed by Eqs. (2), (3) and (4), respectively. 
Citation: Monteiro, W.M.L., and Sarmento, A (2019). Analysing the Possibility of Extracting Energy from Ocean Waves in Cabo-Verde to Produce Clean Electricity - Case-Study: The Leeward Islands. Int. Journal of Renewable Energy Development, 8(1), 103-112,doi.org/10.14710/ijred.8.1.103-112

P a g e $\mid 106$

$\frac{P_{\text {model }}}{P_{\text {protptype }}}=\lambda^{7 / 2}$

$\frac{H_{\text {s model }}}{H_{\text {s prototype }}}=\lambda$

$\frac{T_{\text {p model }}}{T_{\text {p prototype }}}=\lambda^{1 / 2}$

The Capacity Factor (CF) is defined by the ratio between the rated power by model and rated power by the prototype, as represented by Eq. (5)

$C F=\frac{P_{\text {model }}}{P_{\text {prototype }}}$

For each chosen wave device, within the scope of this work, the ratings power in the target region was calculated, for different values of $\lambda$ and the best FC value is identified.

\subsection{The cost - benefits ratio $(C / B)$}

According to Dantas, (2015) the relationship between the cost and benefits (C/B, expressed in [USD/kWh]) for a Wave Energy Converter (WEC) is represented by the following equation, where CEM [USD/kWh] represents the specific Operation and Maintenance cost [USD/kWh], $\mathrm{R}$ is the residual cost [USD], explained below, $\mathrm{I}$ is the initial investment cost [USD], CF represents the Capacity Factor, $\vartheta$ is the useful life cycle [years], PI is the installed Power $[\mathrm{kW}]$ and $\mathrm{i}$ is the interest rate.

$\frac{C}{B}=C E M+\left(I \times i+\frac{(I-R) \times i}{(1+i)^{v / C F}-1}\right) \times \frac{1}{P I \times C F \times 8760}$

One of the biggest problems associated with the offshore WECs is related to their residual cost (R). In fact, for these categories of WECs the International Maritime Laws
(IMO) determines the total removing of their structures, after completing the total useful life cycle of power plant. Hence, the residual cost for offshore WECs is $R=0$ (Baserra, 2007).

The installed Power (PI) is calculated using Eq. (7), in which the $\mathrm{EC}[\mathrm{kWh}]$ is the parameter that represents the energy consumption (Mehta, 2005).

$P I=\frac{E C}{C F \times 8760}$

\subsection{Minimum cost of WECs acquisition}

Because of the small size of Cabo-Verde, and the proximity of its islands, one of the important problems that can arise when installing a wave power plant is related to the available area to build the power plant infrastructure. In fact, this situation should be taken into account whenever the size of the power plant interferes with the national and international shipping lines as well as with the natural reefs, or fishing areas that exist in the installation locations. Thus, whenever the problems of physical restriction are imposed, it is crucial to choose the correct composition of the power plant (amount and type of WECs) that are able to satisfy the needs for electric power at a minimum cost. To achieve this goal, the Linear Programming concept was used (Fox and Garcia, 2013). It is an optimization problem in which the Objective Function (Z) is the total cost of WECs acquisition. The aim is to find the minimum value of $\mathrm{Z}$ function under the restrictions which reflects both the electrical power level required and the maximum number of WECs admissible to reach this power level. The candidate devices are Wave Dragon (7MW), Pelamis (750 kW) and AquaBuoy $(250 \mathrm{~kW})$ for each the capital cost are shown in Table 3.

Table 3

Capital and specific costs of the three WECs analyzed in this work.

\begin{tabular}{lccc} 
& Wave Dragon & Pelamis & AquaBuoy \\
\hline Capital Cost [USD/kW] & 2670.25 & 3958.22 & 890.72 \\
O\&M [USD/kWh] & 0.02 & 0.04 & 0.07 \\
\hline
\end{tabular}

To analyze the influence of the physical limitation on the total cost of power plant, three scenarios of the maximum number of WECs were assumed. The technological matrix to find the optimum value of $\mathrm{Z}$ is expressed by the following set of mathematical condition.

$\operatorname{MinZ}=7000 \times 2670.25 X_{W D}+250 \times 890.72 X_{A B}+750 \times$

3958.22 $X_{P L}$

Under the following restriction:

$$
\left\{\begin{array}{c}
7 X_{W D}+0.25 X_{A B}+0.75 X_{P L}=P I^{j} \\
X_{W D}+X_{A B}+X_{P L} \leq N_{\text {max }}^{j} \\
X_{W D} ; X_{A B} ; X_{P L} \text { are integer positive }
\end{array}\right.
$$

Where, $\mathrm{X}_{\mathrm{WD}}, \mathrm{X}_{\mathrm{AB}}$ and $\mathrm{X}_{\mathrm{PL}}$ are the amount of Wave Dragon, AquaBuoy and Pelamis devices, respectively. $P I^{j}$ and $N_{\max }^{j}$ represent the installed power and the maximum number of WECs allowed for the island $\mathrm{j}$.

Table 4

Data within the cluster.

\begin{tabular}{lcccccc}
\hline \multicolumn{1}{c}{ Parameters } & Cluster one & Cluster two & Cluster three & Cluster four & Cluster five & Cluster six \\
\hline Hs [m] & 6531 & 11640 & 20747 & 9260 & 33712 & 4204 \\
TP [s] & 7395 & 11851 & 22196 & 7899 & 30252 & 4371 \\
Dp [ $\left.{ }^{\circ}\right]$ & 6469 & 12180 & 18103 & 8253 & 27775 & 4379 \\
Vw [m/s] & 7365 & 11928 & 20849 & 7956 & 34255 & 3569 \\
Dw [ $\left.{ }^{\circ}\right]$ & 7388 & 12020 & 21930 & 9538 & 34529 & 4345 \\
Total & 35148 & 59619 & 103825 & 42906 & 160523 & 20868 \\
Percentage & $8.31 \%$ & $14.1 \%$ & $24.5 \%$ & $10.2 \%$ & $37.9 \%$ & $4.90 \%$ \\
\hline
\end{tabular}




\section{Results and Discussion}

The Fig.10 shows the scatter plots of the wave and wind parameters obtained through SOWFIA. The figure shows the distribution curves of the referred parameters and the coefficient of correlation between them. The linear regression lines and the centroid (the point on the curve) of any possible combination of these wave and wind characteristics are also shown in Fig.10. These plots revealed strong evidence that shows that none of these parameters follow the Normal Distribution curves because their values are not equally distributed around the average (axis of symmetry). However, the data of the wind velocity seem to approximate significantly from Normal behavior. Thus, to analyse the nature of these data it is necessary to use the tools of Non-Parametric statistics. As Fig. 10 shows, there is some moderate correlation between the significant wave height and the wind velocity $(0.47)$, and between the wave peak period and the wave peak direction (0.41). That means that the significant wave height and the peak period tend to be positively influenced by wind velocity and wave direction, respectively. The correlation between the remaining parameters is very weak and, in some cases, nonexistent.

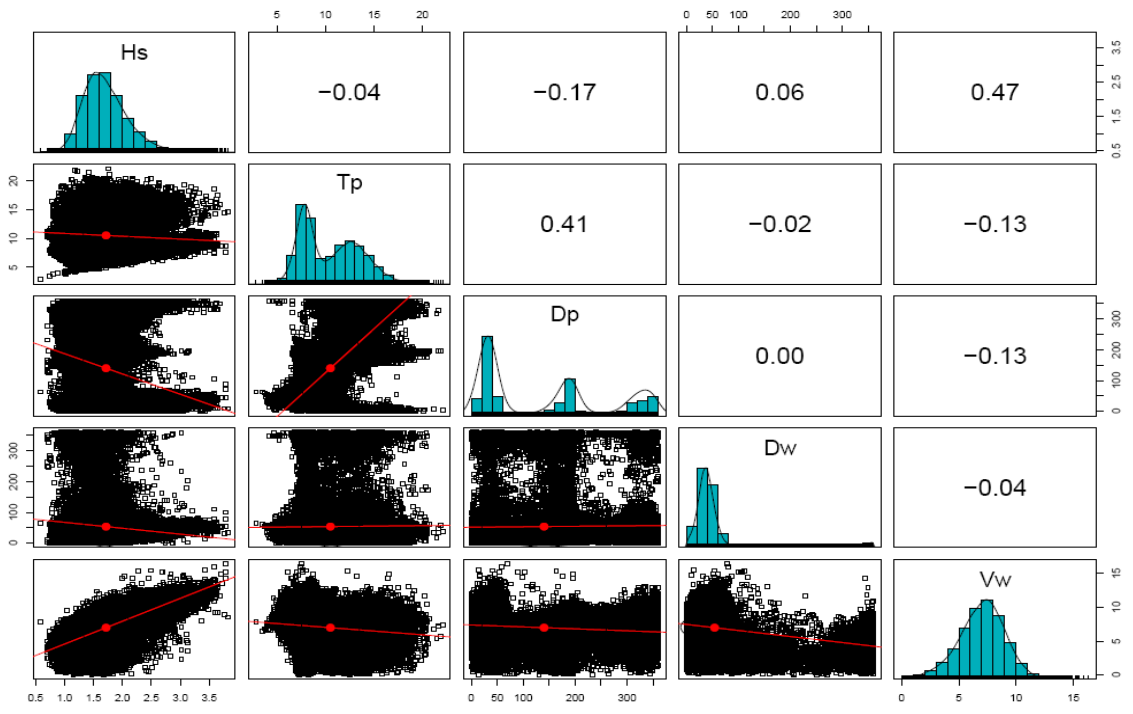

Fig.10 Results produced by R Software.

Using the $\mathrm{R}$ software, the cluster analysis by the k-mean method was carried out. The best value of $\mathrm{k}$ parameter was calculated using the GMDH software. The results of this statistic procedure generated six clusters of waves and their content is presented in Table 4 . The waves and wind in cluster five are the most predominant (37.9\%), followed by those in cluster three (24.5\%).

The content of the cluster six is the poorest $(4.903 \%)$ and the clusters, one, two and five presented, respectively, $8.31 \%, 14.1 \%$ and $10.20 \%$ of the data.

The dispersion measurement of the data within each cluster, through their Coefficient of Variation, was calculated and presented in Table 5. According to the values shown in the present table, $80 \%$ of the data within the clusters show low and moderate dispersion $(\mathrm{COV}<30 \%)$. The wind data, especially the wind direction parameter, tend to be more disperse, presenting $\mathrm{COV}$ between $36 \%$ and $46 \%$.
Using the Non-Parametric Wilcoxon Test, the representative values of each wave and wind parameters in each cluster were identified and shown in Table 6. These representative values constitute the input parameters for SWAN. For all these parameters, the NonParametric Wilcoxon test produced p-values higher than 0.05 (Table 7) that means the acceptance of each substitute value.

To perform the wave transformation from the location of data acquisition to the shore, the bathymetric information is required. The bathymetric chart, for the area of study (Fig.11), was obtained through the British Oceanographic Data Centre (BODC, 2018). This bathymetric grid is characterized by the geographic coordinate of its corner $\left(\mathrm{x}_{\text {corner }}=-25.3320\right.$ and $\mathrm{y}_{\text {corner }}=$ 15.9257, in decimal degree), number of columns $\left(\mathrm{n}_{\text {columns }}=\right.$ $349)$ and rows $\left(\mathrm{n}_{\text {rows }}=228\right)$ and its spacing in the $\mathrm{x}(\mathrm{dx}=$ 0.09 ) and y directions (dy $=0.09$, in decimal degree).

Table 5

Coefficient of Variation of the data within the cluster.

\begin{tabular}{lcccccc}
\hline \multicolumn{1}{c}{ Parameters } & Cluster one & Cluster two & Cluster three & Cluster four & Cluster five & Cluster six \\
\hline Hs [m] & $15.4 \%$ & $20.0 \%$ & $15.6 \%$ & $23.2 \%$ & $18.9 \%$ & $15.7 \%$ \\
TP [s] & $11.1 \%$ & $13.0 \%$ & $18.2 \%$ & $8.4 \%$ & $11.3 \%$ & $25.6 \%$ \\
Dp [ $\left.{ }^{\circ}\right]$ & $3.3 \%$ & $3.1 \%$ & $5.8 \%$ & $25.7 \%$ & $19.3 \%$ & $58.1 \%$ \\
Vw [m/s] & $21.7 \%$ & $22.3 \%$ & $26.4 \%$ & $36.1 \%$ & $23.4 \%$ & $40.9 \%$ \\
Dw [ ${ }^{\circ}$ ㅇ․ & $39.3 \%$ & $37.2 \%$ & $46.1 \%$ & $11.7 \%$ & $30.7 \%$ & $4.9 \%$ \\
\hline
\end{tabular}


Citation: Monteiro, W.M.L., and Sarmento, A (2019). Analysing the Possibility of Extracting Energy from Ocean Waves in Cabo-Verde to Produce Clean Electricity - Case-Study: The Leeward Islands. Int. Journal of Renewable Energy Development, 8(1), 103-112,doi.org/10.14710/ijred.8.1.103-112

$\mathrm{P}$ a g e 108

Table 6

Input parameter for SWAN.

\begin{tabular}{lccccc}
\multicolumn{1}{c}{ Parameters } & Cluster one & $\begin{array}{c}\text { Cluster } \\
\text { two }\end{array}$ & $\begin{array}{c}\text { Cluster } \\
\text { three }\end{array}$ & $\begin{array}{c}\text { Cluster } \\
\text { four }\end{array}$ & $\begin{array}{c}\text { Cluster } \\
\text { five }\end{array}$ \\
\hline Hs [m] & 1.51 & 1.68 & 1.51 & 1.82 & 1.795 \\
TP [s] & 12.89 & 12.95 & 12.74 & 7.80 & 7.806 \\
Dp [ $\left.{ }^{\circ}\right]$ & 306.99 & 340.7 & 188.3 & 36.60 & 31.9 \\
Vw [m/s] & 6.906 & 7.206 & 6.30 & 7.28 & 7.75 \\
Dw [ ${ }^{\circ}$ ] & 39.04 & 38.07 & 33.25 & 59.67 & 34.88 \\
\hline
\end{tabular}

Table 7

P-values of Wilcoxon Test.

\begin{tabular}{|c|c|c|c|c|c|c|}
\hline Parameters & $\begin{array}{c}\text { Cluster } \\
\text { one }\end{array}$ & Cluster two & $\begin{array}{c}\text { Cluster } \\
\text { three }\end{array}$ & $\begin{array}{c}\text { Cluster } \\
\text { four }\end{array}$ & $\begin{array}{c}\text { Cluster } \\
\text { five }\end{array}$ & Cluster six \\
\hline $\mathrm{Hs}[\mathrm{m}]$ & 0.5806 & 0.1116 & 0.7309 & 0.6321 & 0.779 & 0.7694 \\
\hline $\mathrm{TP}[\mathrm{s}]$ & 0.07022 & 0.1187 & 0.2705 & 0.3924 & 0.2308 & 0.9515 \\
\hline $\mathrm{Dp}\left[{ }^{\circ}\right]$ & 0.08638 & 0.08081 & 0.9767 & 0.7901 & 0.2286 & 0.9009 \\
\hline $\mathrm{Vw}[\mathrm{m} / \mathrm{s}]$ & 0.2684 & 0.1001 & 0.1509 & 0.09684 & 0.2486 & 0.9807 \\
\hline $\mathrm{Dw}\left[^{\circ}\right]$ & 0.9217 & 0.2584 & 0.1016 & 0.478 & 0.1208 & 0.9198 \\
\hline
\end{tabular}

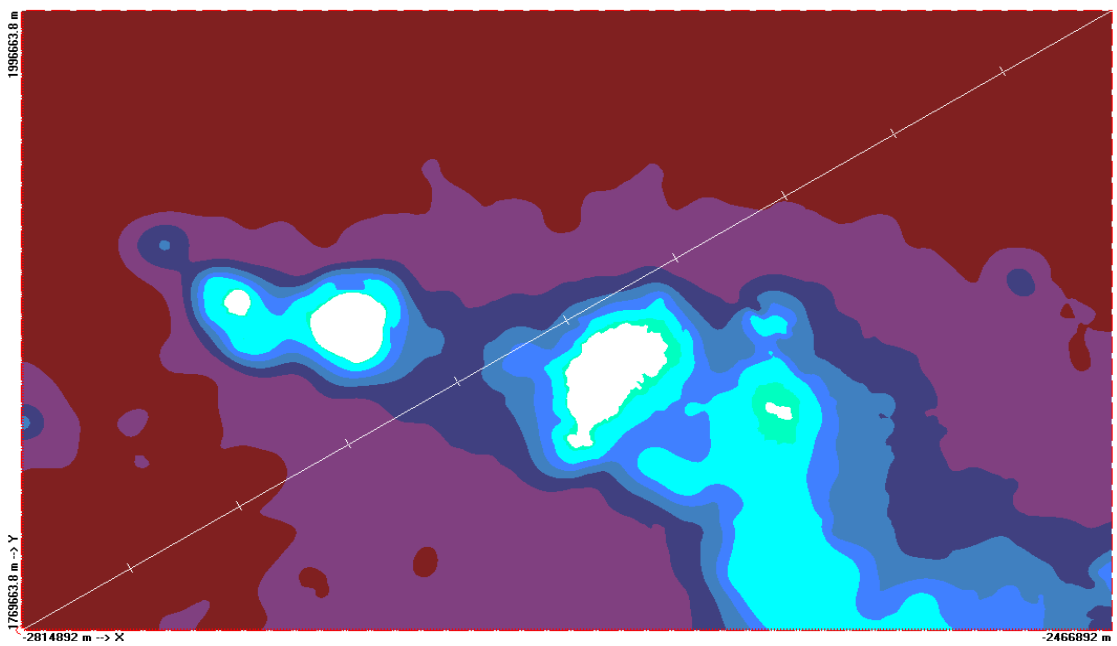

Fig.11 Bathymetry map of leeward island of Cabo-Verde.

Analyzing the isolines of the significant wave height, produced by SWAN and showed in Figs. 12 to 17, it's possible to identify the best locations for installing the wave power plant. As Fig.12 (cluster 1) shows, the highest values of significant wave height (between $1.0 \mathrm{~m}$ and $2.6 \mathrm{~m}$ ) are found in the south region of the target islands. This situation is verified for waves within the clusters two, four and five, for which the highest values of the significant wave height are, respectively, between $2.0 \mathrm{~m}$ and $2.2 \mathrm{~m}$ (Fig.13) and around $1.8 \mathrm{~m}$ (for the remaining clusters Figs. 15 and 16). However, as the Figs. 14 and 17 show, the situation is reversed for waves within the clusters three and six, for which the highest values of the significant wave height occur in the Northern of the islands. For these waves, the values of the significant wave height vary between $1.6 \mathrm{~m}$ and $2.0 \mathrm{~m}$ at the best locations. In general, the results showed that $70.52 \%$ of the waves (cluster one, two, four and five) pointed to the South of the islands as the best location for wave energy extraction, with significant wave height between $1.0 \mathrm{~m}$ and $2.6 \mathrm{~m}$ and peak period between $7.8 \mathrm{~s}$ and $12.95 \mathrm{~s}$. The remaining waves, corresponding to $29.58 \%$ (clusters three and six), revealed that the North part of the islands is the best location for installing wave power plant, for which the significant wave height varies between $1.6 \mathrm{~m}$ and $2.0 \mathrm{~m}$ for peak period varying from 10.74 to 12.74 . The distant region of the East Coast of Maio Island always presents good conditions for wave energy application, with significant wave height between $1.5 \mathrm{~m}$ and $2.56 \mathrm{~m}$. In general, the regions near the shorelines have significant wave height that is less than $1.2 \mathrm{~m}$, suggesting more deep studies to show the viability associated with the wave energy utilization in these regions.

The power captured by a WEC in a known sea state is commonly represented in terms of significant wave height and wave period (peak period, energy period or mean wave period), on table format known as Power Matrix. The Power Matrix allows the transfer of the performance of a WEC in a known sea state to many locations around the world. Figs. 18 to 20 show the power matrices of Pelamis (Henderson, 2006), Wave Dragon (Kofoed et al., 2006) and AquaBuoy (Weinstein, 2004), respectively that represents the wave devices under the present study. Analysing the values of power captured shown in these tables it is evident that there are some combinations of significant wave height and wave period for which these machines do not capture any power. 


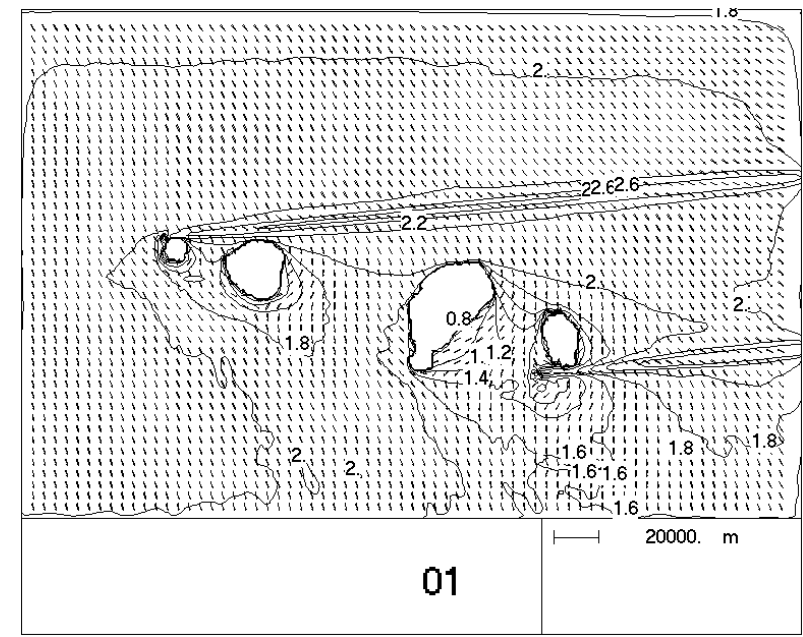

Fig.12 Cluster one.

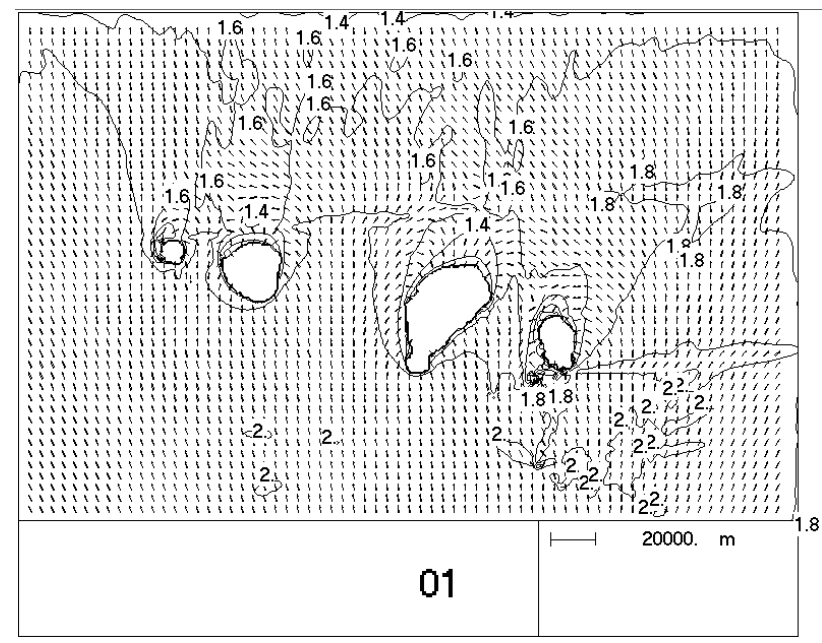

Fig.14 Cluster three.

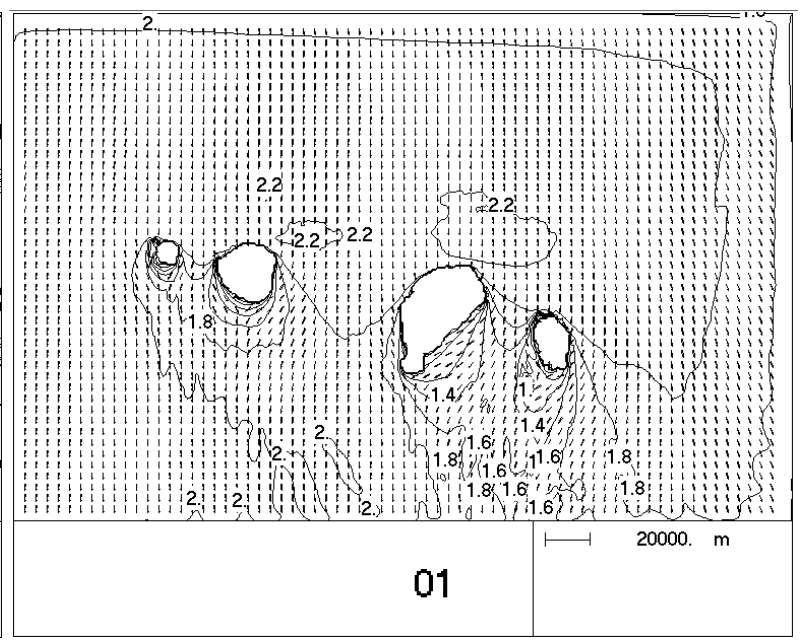

Fig.13 Cluster two.

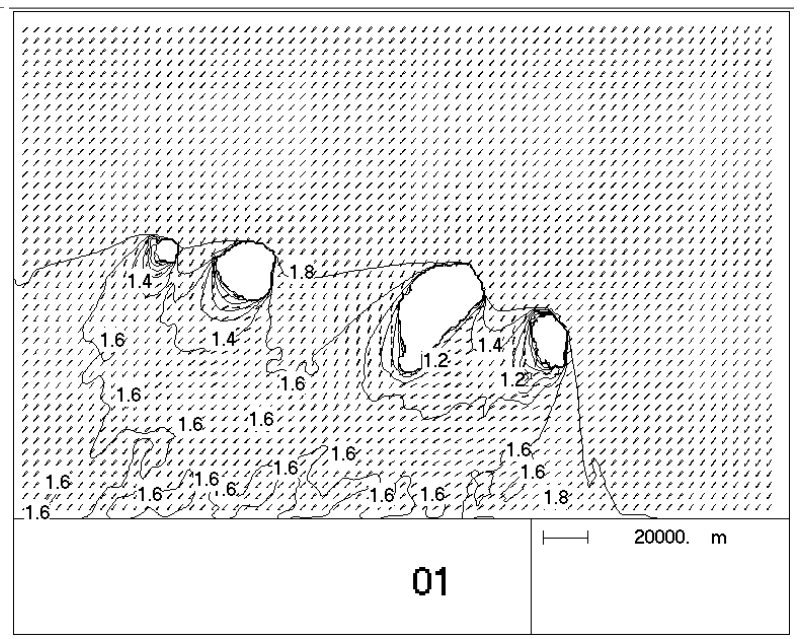

Fig.15 Cluster four

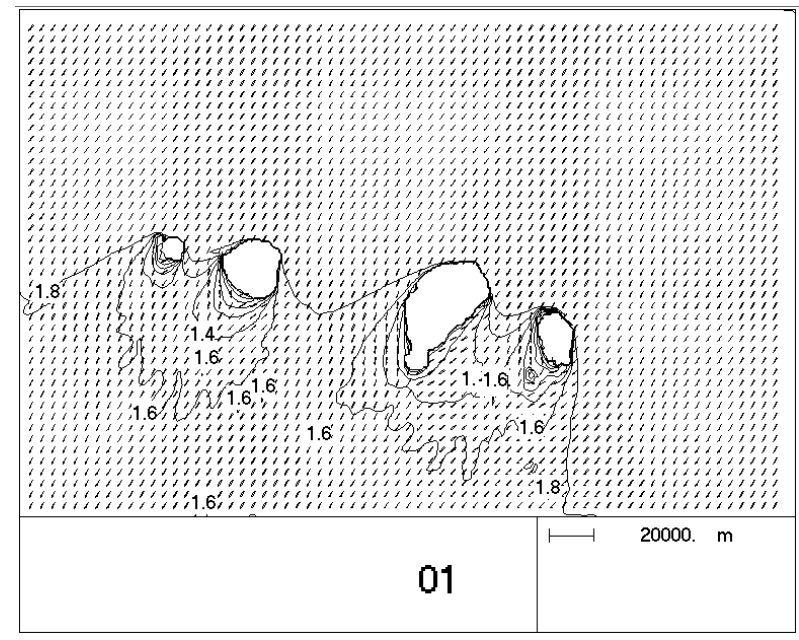

Fig.16 Cluster five.

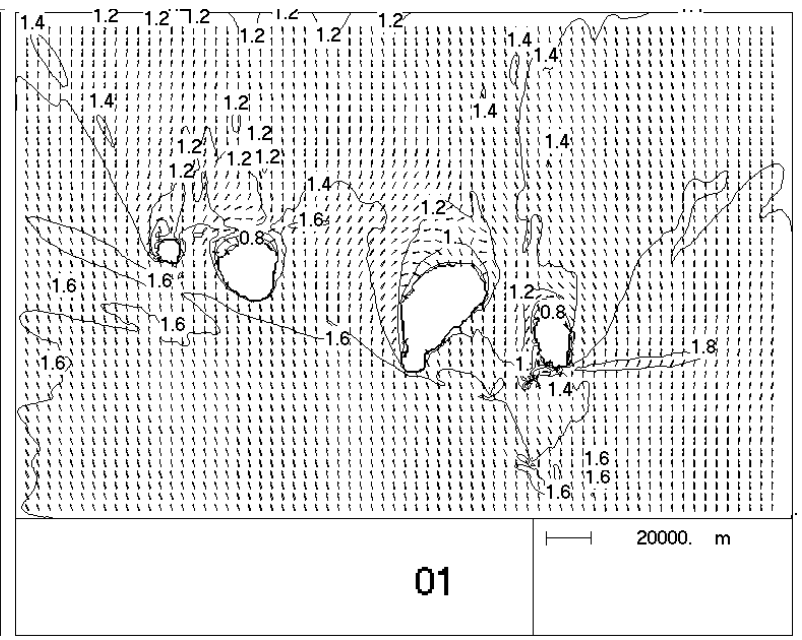

Fig.17 Cluster six 


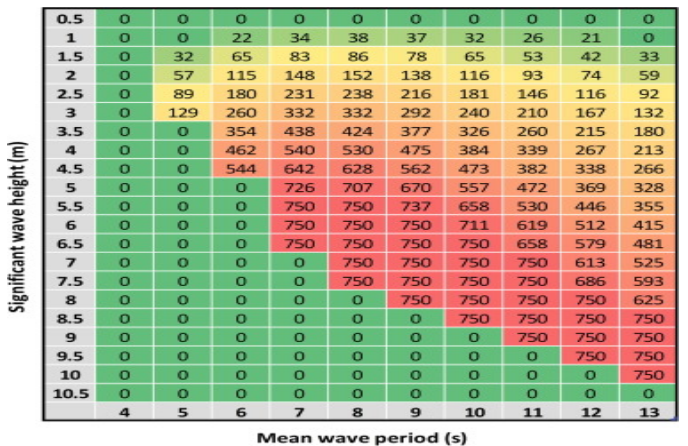

Fig. 18 Pelamis' Power Matrix

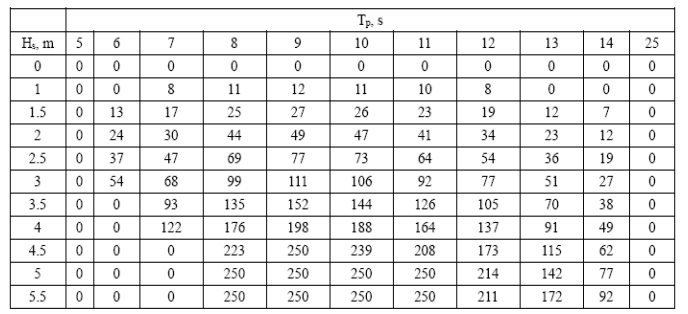

Fig.20 AquaBuoy' Power Matrix

In general, these devices begin to capture power for significant wave height from de $1 \mathrm{~m}$ and for wave period from de $5 \mathrm{~s}$ as is the case of Pelamis and Wave Dragon (Figs. 18 and 19) and from 7s for AquaBuoy (Fig.20). The limit values of significant wave height and wave period from which these machines fail to capture power are 10.5 $\mathrm{m} \mathrm{e} 13 \mathrm{~s}$ (Pelamis), $7 \mathrm{~m}$ and $17 \mathrm{~s}$ (Wave Dragon) and $5.5 \mathrm{~m}$ and $14 \mathrm{~s}$ (Aqua Buoy). To analyse the performance of the three devices under this study, their power matrix was scaled according to Eqs. (2 to 4 ) and the scale factor that lead to the best device efficiency was identified. Yet, the efficiency of these devices was also calculated considering their natural size. Thus, based on the devices' power matrix (Fig. 18 to 20), the Capacity Factor (CF) of the Wave Dragon (WD), AquaBuoy (AB) and Pelamis (PL) for the most promised offshore location around the islands was calculated and plotted as a function of their scale factor (Fig.21). As the Fig.21 shows, the Wave Dragon is the best device at a scale $\lambda=0.3$, presenting $\mathrm{CF}=71.48 \%$, followed by AquaBuoy $(\lambda=0.4$ and $\mathrm{CF}=56.8 \%)$ and Pelamis $(\lambda=$ 0.5 and $\mathrm{CF}=25.64 \%)$ respectively. However, in a natural scale, the AquaBuoy presented higher value of CF (18.8\%), followed by Wave Dragon (17\%) and Pelamis (15.5\%).

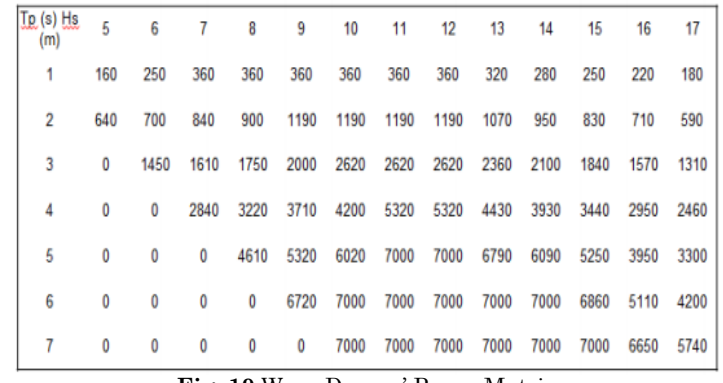

Fig. 19 Wave Dragon' Power Matrix

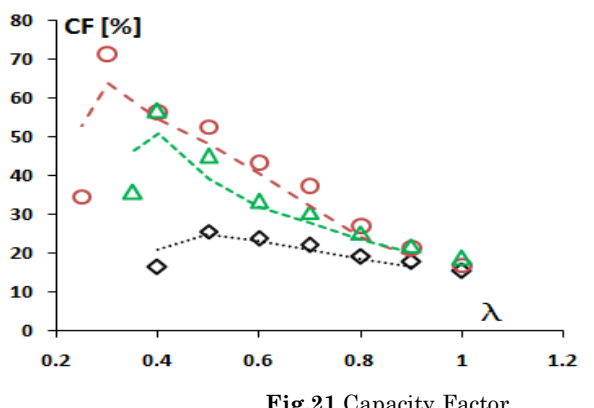

PELAMIS

OWAVE DRAGON

$\triangle$ AquaBuoY

Based on the $\mathrm{CF}$ values, it seems that Pelamis is the least indicated device among those three analyzed in this study. Another very important aspect to refer to when analysing the feasibility of a wave energy power plant, is the ratio between the cost of energy and its benefits $(\mathrm{C} / \mathrm{B})$. That amount is calculated for a wave power plant with the installing capacity able to providing all electrical power needed for Fogo, Brava and Maio islands and 15\% of energy consumption on the biggest island (Santiago). The most recent information about electrical power consumption from fuel fossil power plant in the target islands are published in Electra (2016) and presented in Table 1.

Considering the values of FC obtained for the different devices, at natural scale, analysed in this study and using the Eq. (7) the respective installing capacity and its associated number of the WECs were calculated and presented in Table 8 . Thus, to respond the need for all the electrical power consumption in Fogo, Brava and Maio it is necessary to build wave power plant with, respectively, $10 \mathrm{MW}, 2 \mathrm{MW}$ and $2 \mathrm{MW}$ of installing capacity.

To provide $15 \%$ of all electrical power needed for Santiago Island it is necessary $21 \mathrm{MW}$ wave power plants.

Table 8

Installing Wave Power Plant Capacity for the target islands

\begin{tabular}{|c|c|c|c|c|c|c|c|}
\hline \multirow[b]{2}{*}{ Island } & \multicolumn{7}{|c|}{ Installing Power [MW] and the Number of WEC unities } \\
\hline & PI $[\mathbf{M W}]$ & WD & Number of WD & $\mathbf{A B}$ & $\begin{array}{c}\text { Number of } \\
\text { AB }\end{array}$ & PL & Number of PL \\
\hline Santiago & 21 & 128 & 19 & 115 & 460 & 140 & 186 \\
\hline Maio & 2 & 2 & 1 & 2 & 7 & 2 & 3 \\
\hline Fogo & 10 & 10 & 2 & 9 & 33 & 10 & 14 \\
\hline Brava & 2 & 2 & 1 & 2 & 7 & 2 & 3 \\
\hline
\end{tabular}


Table 9

Results of the Linear Programming procedure

\begin{tabular}{|c|c|c|c|}
\hline Islands & $\begin{array}{c}\text { Maximum number } \\
\text { of WECs }\end{array}$ & $\begin{array}{c}\text { Minimum Capital Cost } \\
\text { [MilionUSD] }\end{array}$ & $\begin{array}{l}\text { Wave Power Plant } \\
\text { Composition }\end{array}$ \\
\hline 党 & $\begin{array}{l}30 \\
24 \\
20\end{array}$ & $\begin{array}{l}43.6 \\
50.5 \\
55.1\end{array}$ & $\begin{array}{c}\text { 2WD+28PEL } \\
2 \mathrm{WD}+19 \mathrm{AB}+3 \mathrm{PEL} \\
2 \mathrm{WD}+13 \mathrm{AB}+5 \mathrm{PEL}\end{array}$ \\
\hline 事 & $\begin{array}{l}9 \\
7 \\
5\end{array}$ & $\begin{array}{l}25.9 \\
28.3 \\
30.6\end{array}$ & $\begin{array}{c}1 \mathrm{WD}+6 \mathrm{AB}+2 \mathrm{PEL} \\
1 \mathrm{WD} 3 \mathrm{AB}+3 \mathrm{PEL} \\
1 \mathrm{WD}+4 \mathrm{PEL}\end{array}$ \\
\hline 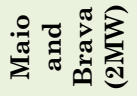 & $\begin{array}{l}8 \\
6 \\
4\end{array}$ & $\begin{array}{l}1.8 \\
4.1 \\
6.4\end{array}$ & $\begin{array}{c}8 \mathrm{AB} \\
5 \mathrm{AB}+1 \mathrm{PEL} \\
2 \mathrm{AB}+2 \mathrm{PEL}\end{array}$ \\
\hline
\end{tabular}

Using these values of installed capacity, together with the information about the Capital and O\&M costs (Table 3) and assuming $\mathrm{R}=0$ (recommended residual value for offshore devices), the values of the $\mathrm{C} / \mathrm{B}$ ratio for all of three devices were calculated for a power plant with 30 years of life cycle and assuming a $12 \%$ interest rate. The AquaBuoy presented the best C/B ratio (0.135 USD/kWh), followed by Wave Dragon $(\mathrm{C} / \mathrm{B}=0.235 \mathrm{USD} / \mathrm{kWh})$ and Pelamis $(\mathrm{C} / \mathrm{B}=0.390 \mathrm{USD} / \mathrm{kWh})$. Again, the Pelamis present the worst results compared with the remaining devices.

The values of $\mathrm{C} / \mathrm{B}$ ratio are crucial as it helps choose the best wave technology of conversion, because for the final consumer the most important aspect is to pay the least possible for the energy. For Fogo, Brava and Maio islands the installed capacities are not very high. Thus, it is possible to fully complete the electrical energy needs of these islands with wave energy and transforming them into $100 \%$ renewable islands. However, the wave installed capacity of Santiago Island is very high and the possibility to satisfy all electrical energy needs of this island only by wave energy would probably be unfeasible. Another problem associated with wave energy extraction in CaboVerde is related to the area available to build the power plant. This situation becomes more problematic whenever the numbers of devices to be installed is very high. In this context, taking into consideration the dimension of the wave devices, the proximity of the islands, the allocation of the fishing area and the national and international lines of maritime traffic, the number of devices should be limited. The maximum number of the devices that are allowed for each island could be a result of a deep study to carry on along with the Maritime and Port Institute of Cabo-Verde. However, to analyze the effect of limiting the number of the devices on a minimum investment cost of each wave power plant, three different scenarios is taken into account (Table 9). For each scenario, three values for the maximum number of WECs are chosen and the minimum capital cost and the power plant composition (number and type of WECs) are, respectively, calculated and shown in Table 9. The Minimum cost and the composition of the power plant shown in the referred table were calculated using Linear Programming tools. From this table it is very evident that the total investment cost decreases significantly when the maximum number of devices increases, suggesting a strong commitment between the cost, and the area that is available to build the power plant.

\section{Conclusion}

This work deals with the evaluation of the real possibility to extract useful energy from the ocean waves around the Leewards Islands of Cabo-Verde. The study was based on a 31 years of wave and wind data obtained using SOWFIA at the middle of the country $\left(16^{\circ} \mathrm{N}-24^{\circ} \mathrm{W}\right)$ where the water depth is $3.7 \mathrm{kms}$. Then the SWAN was used to perform the wave transformation to the shorelines of the target islands.

The nature of the data collected in the middle of the country was carefully analyzed. In this context, the Scatter Plots reveal some moderate correlation between significant wave height and wind velocity, between the wave peak period and the wave peak direction and very weak or nonexistent correlation between the remains parameters. Yet, these plots make evident the NonNormal Distribution nature of the data. Thus, the NonParametric statistics, along with the cluster analysis, showed that the entire data can be reorganized in 6 groups of data. Each group contains wave and wind data with similar characteristics, presenting, in general, low and moderate dispersion. This procedure helped identify the most and least frequent groups of waves and winds. Nonetheless, using the same procedure allied to the realization of the Non-Parametric Wilcoxon-Test each group of data was substituted by a unique combination of wave and wind data which constituted, along with bathymetric data, the SWAN' input information, reducing drastically the computing time by SWAN. According to the results produced by SWAN, $70.52 \%$ suggest that the South of the islands is the best location for convert wave energy. The East Coast of Maio is another privileged location for this purpose. For these locations, the significant wave height and the peak period vary between $1.0 \mathrm{~m}$ and $2.6 \mathrm{~m}$ and $7.8 \mathrm{~s}$ and $12.95 \mathrm{~s}$, respectively. The most suitable devices for this wave climate is the Wave Dragon at a scale $\lambda=0.3$, presenting $\mathrm{CF}=71.48 \%$, followed by AquaBuoy $(\lambda=$ 0.4 and $\mathrm{CF}=56.8 \%)$ and Pelamis $(\lambda=0.5$ and $\mathrm{CF}=$ $25.64 \%$ ), respectively. At natural scale, AquaBuoy is the device being choisen since it presented best $\mathrm{CF}$ and $\mathrm{C} / \mathrm{B}$ ratio values $(\mathrm{CF}=18.8 \%$ and $\mathrm{C} / \mathrm{B}=0.135 \mathrm{USD} / \mathrm{kWh})$ in comparison with Wave Dragon $(\mathrm{CF}=17 \%$ and $\mathrm{C} / \mathrm{B}=0.235$ $\mathrm{USD} / \mathrm{kWh})$ and Pelamis $(\mathrm{CF}=15.5 \%$ and $\mathrm{C} / \mathrm{B}=0.390$ $\mathrm{USD} / \mathrm{kWh}$ ). The limitation of the area available for installing a wave power plant affects adversely the total cost of the project. 


\section{Acknowledgment}

Firstly, I would like to offer my special thanks to Dr. Nico Booji from Delft University, for providing the version of the SWAN with User Interface. Secondly, I am particularly grateful for the continuous assistance given by Juana Fortes and Pedro Poseiro from LNEC in using the SWAN software. Finally, I would like to thank my colleague António Fernandes and Paulo Jorge Lopes Borges for their important contribution and suggestion for the completion of this work.

\section{References}

Baserra, E.R. (2007) Avaliação de Sítios para aproveitamento dos recursos Energéticos das Ondas do Mar, Universidade Federal do Rio de Janeiro, Rio de Janeiro, Brasil.

Bholowalia, P. and Kumar, A. (2014) EBK - Mean: A Cluster Technique Based on Elbow Method and k-mean in WSN, International Journal of Computer Applications, 105( 9).

BODC.(2018). British Oceanographic Data Centre: https://www.bodc.ac.uk. Accessed 2018.

Booji, N., Ris, R.C., Holthuijsen, L.H. (1999) A third-generation wave model for coastal regions, Part I, Model description and validation, J.Geoph Research, 104(C4).

Boyle, G. (2004) Renewable Energy: Power for a Sustainable Future, 2nd Ed., Oxford University Press, Oxford.

Carvalho, J.M.C. (2013) Elaboration of Third International Conference on Sustainable Development in Small Island States in Development, United Nations Development Program, National Report, Republic of Cape-Verde

CSIRO (2012) Ocean Renewable Energy: An Analysis of Ocean Energy

in Australia.http://www.csiro.au/ /Media/BEA2D117313c4 98BAD26624BOBE911F9.ashx. Accessed 2018.

Dantas, C.E.B. (2015) Estudo dos Conversores de Energia Ondomotriz em Energia Eléctrica, Faculdade de Tecnologia, Departamento de Mecânica, Universidade de Brasília, Brasil.

Electra, Relatório de Contas 2012. ElectraEmpresa de Electricidade e Água, Cabo-Verde, http://www.electra.cv/index.php/2014-05- 20-15-4704/relatorios-sarl. Accessed 2012.

Electra, Relatório de Contas 2016. ElectraEmpresa de Electricidade e Água, Cabo-Verde, http://www.electra.cv/index.php/2014-05- 20-15-4704/relatorios-sarl. Accessed 2016

EMEC - Wave devices page. http://www.emec.org.uk/marineenergy/wave-devices/. Accessed 2018.

Fox, W.P. and Garcia, F.P. (2013) Modeling and Linear Programming in Engineering Management, Intech, ISBN 978-953-51-1037-8.

GESTO (2011) Plano Energético Renovável CaboVerde. GestoEnergy Solutions, Algés, Portugal.

Henderson, R.(2006) Design, Simulation and Testing of a Novel Hydraulic Power Take-Off System for the Pelamis Wave Energy Converter, Energy, 31.

Hughes. S.A. (1993) Physical Models and Laboratory Techniques in Coastal Engineering, Coastal Engineering Research Center, Waterways Experiment Station, World Scientific, USA.

Kempner, R. (2014) Ocean Energy Technology Brief 4, International Renewable Energy Agency - IRENA.

Koca, K., Oumeraci, H., Angelelli, E., Suffredini, R. Kortenhaus,A., Zanuttigh,B. Cantù,M. and Franceschi, G. (2013) Recent Advance in the Development of Wave Energy Converters, Proc. EWTEC'2013 - European Wave and Tidal Energy Conference, Aalborg, Denmark.

Kofeod, J.P., Frigaard, P., Friis - Madsen, E., Sorensen, H.C., (2006) Prototype Testing of the Wave Energy Converter Wave Dragon, Energy, 31.
Komen, G.J., Cavaleri, I., Donelan, M., Hasselmann, K., Hasselmann, S., and Janssen, P.A.E.M. (1994) Dynamics and modelling of ocean waves, Cambridge University Press, Cambridge.

Mackay, E.B.L., Baha, J A.S. and Challenor, P.G. (2010) Uncertainty in wave energy resource assessment. Part 2: Variability and predictability, Renewable Energy, 35.

Mehta, V.K. and Mehta, R.T. (2005). Principles of Power System, revised edition, S.Chand and Company LTD, AN ISO 9001:2000, Ram Nagar, New Delhi - 10055.

Monteiro, W.M.L. and Sarmento, A. (2014) Cape-Verde Offshore Wave Energy Resources Characterization, proc. AWTEC'2014-GRAND RENEWABLE ENERGY, Tokyo Big Sight, Japan.

Monteiro, W.M.L., Sarmento, A., Fernandes, A. and, Fernandes, J. (2017). Statistical Analysis of Wave Energy Resources Available for Conversion at Natural Caves of Cape-Verde Islands, International Journal of Renewable Energy Sources, 2.

Mora-Figueroa, V.O., Olivares, C.H., Holmes, B., and O'Hagan, A.M. (2011) Sowfia - Streamlining of Ocean Wave Farms Impact Assessment, Catalogue of Wave Energy Test Centres, IEE/09/809/SI2.558291, March.

Nakayama, Y. and Boucher, R.F. (1999) Introduction to Fluid Mechanics, Butter worth Heinemann, Oxford.

Norusis, M.J. (2010) Chapter 16, Cluster Analysis, PASW Statistics 18 Statistical Procedures Companion, Upper Saddle River, NJ.

Payne, G. (2008) Guidance for the Experimental Tank Testing of Wave Energy Converters, Supergen Marine.

Pelamis (2014) Pelamis Technology. http://www.pelamis.com/pelamis technology. Accessed 2018.

Salter,S. (1974) Wave Power, Nature.

Selenec, Rapport Annuel (2015), Selenec - SociétéNational d'ÉléctricitéduSénégal, Senegal (2015).

Siocean (2014) Ocean Energy: Cost of Energy and Cost Reduction Opportunities. http://siocean.eu/en/upload/docs/140037Siocean-report-web.pdf. Accessed 2018.

Tan, P-N., Steinbach, M. and Kumar, V. (2005) Cluster Analysis; basic concepts and algorithms In: Introduction to data Mining, Addison-Wesley, Upper Saddle River, N.J.

Tolman, H.L. (1999) User manual and system documentation of Wave Watch-III version 1.18, OMB Tchecnical Note 166, N.O.A.A, National Centre for Environmental Prediction, MD, USA.

Wave 2oTM-Clean Water from Ocean Waves, Wave 2oTM in Cabo-Verde: water.eu/sites/default/files/01\%20$\% 20$ Wave2O\%20in\%20Cape\%20Verde.pdf. Accessed 2015.

Weaver, K.F., Morales, V., Dunn, S.L., Godde, K. and Weaver, P.F. (2017) Statistical Analysis in Research: with applications in the biological and life sciences, Jhon Wiley and Sons. Inc, Hoboken, NJ, USA.

Weinstein, A., Fredikson, G. Parks, M.J., Neilslen, K. (2004) Aqua Buoy - The Offshore Wave Converter. Numeric Modeling and optimization. Proceedings of Oceans'04 MIS/IEE Techo Ocean'04, Kobe, Japan, November, 2004. 